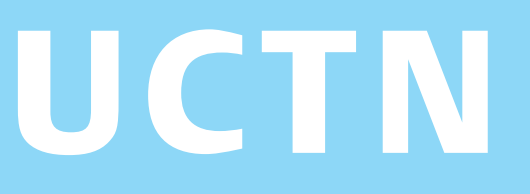

In April 2005, a 44-year-old man with acute bleeding from esophageal varices underwent endoscopic variceal ligation with four detachable Olympus endoloops (MAJ-339; Olympus Optical Co., Tokyo, Japan) at a local hospital. In May 2005, because of recurrent bleeding from gastric fundal varices, he was referred to our hospital. His gastric varices were injected with tissue glue and residual esophageal varices were ligated with four rubber bands. During this procedure, we found an endoloop that had been retained in the sloughing ulcer in the esophagus, nearly $35 \mathrm{~cm}$ from the incisor teeth (Figure 1). A follow-up esophgaogastroduodenoscopy in September 2005 revealed that this endoloop was tightly embedded in the scarring mucosa, in the shape of a dangle earring (Figure 2 ). It looked as if this endoloop would never be extruded spontaneously and, although it was asymptomatic, we dissected the overlying mucosa using a needle-knife (Olympus KD-1L-1, 30 watts, four pulses) and carefully removed it.

Hepworth et al. [1] found that endoloops were no longer by day 37 (median 15 days) after endoscopic variceal ligation. Naga et al. [2] found endoloops still attached to the underlying tissue for 4 weeks in two of their 25 patients who had undergone endoscopic variceal ligation with endoloops. To our knowledge, no endoloop has remained attached for as long as occurred in our case. Endoloops exert a greater compressive force on tissue than elastic bands [3]. However, it is difficult to make an accurate judgment of the tension applied to the loop before its deployment [3], and this is probably why endoloops can become tightly embedded, as in this case. So far, no complication associated with a retained endoloop has been reported. Although leaving it in the mucosa should not be a potential health concern, there is a possibility that the retained loop might cause trapping of fibrous food at some time in the future. In conclusion, it was possible to remove the embedded endoloop safely and easily by

\title{
Embedded detachable endoloop after endoscopic variceal ligation
}
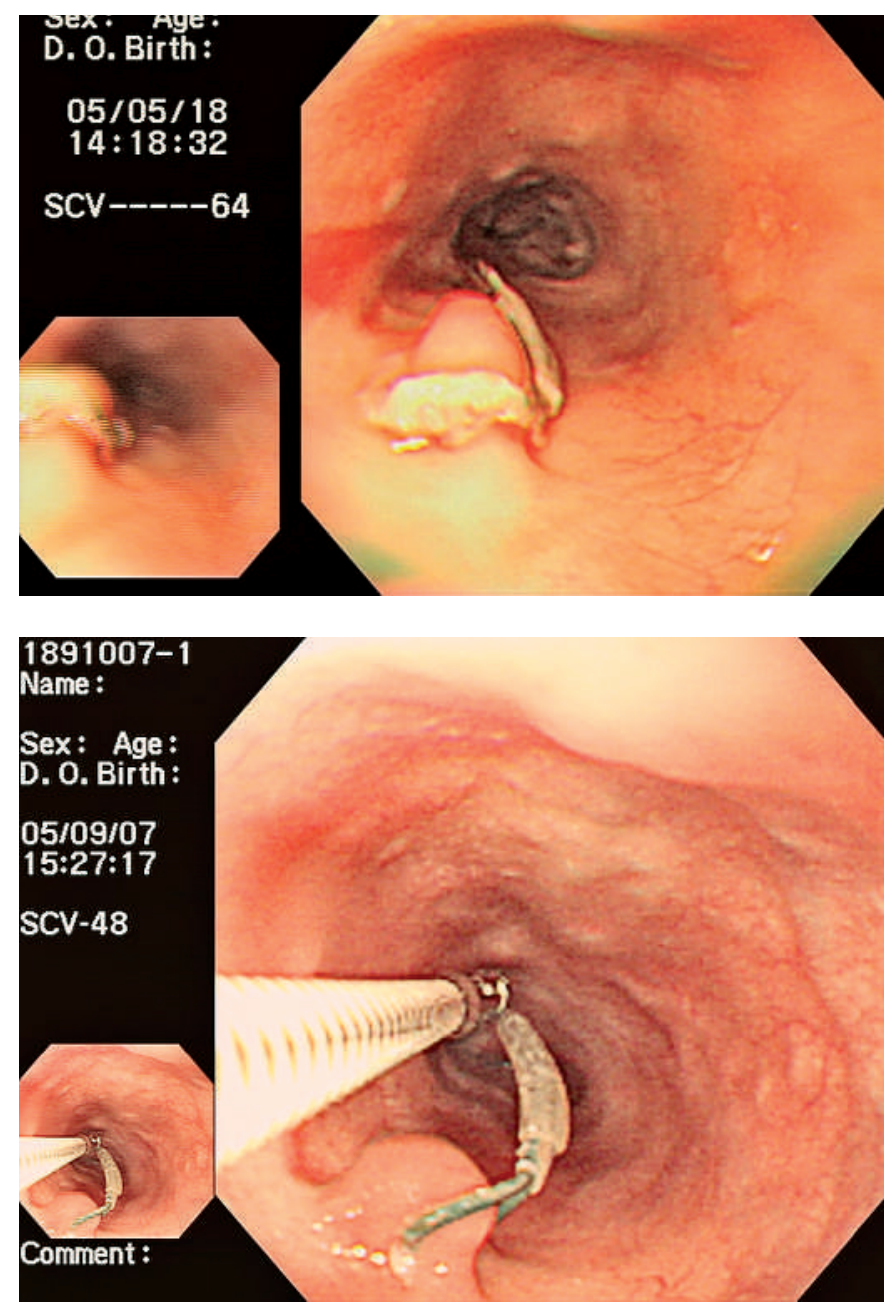

Figure 2 The endoloop was found to be tightly embedded in the scarring mucosal fold in September 2005.
Figure 1 Endoscopic examination in May 2005, 1 month after endoscopic variceal ligation, revealed that a detachable endoloop had been retained in an area of sloughing ulceration, $35 \mathrm{~cm}$ from the incisor teeth. cutting the overlying mucosa using a needle-knife incision. It is therefore unneccessary to avoid using endoloop to ligate varices for fear of loop embedding.

Endoscopy_UCTN_Code_CPL_1AH_2AC Endoscopy_UCTN_Code_TTT_1AO_2AD

\section{W.-C. Liao, M.-C. Hou, H.-C. Lin,}

\section{F.-Y. Chang, S.-D. Lee}

Division of Gastroenterology, Department of Medicine, Taipei Veterans General Hospital and National Yang Ming University School of Medicine, Taipei, Taiwan.

\section{References}

${ }^{1}$ Hepworth CC, Burnham WR, Swain CP. Development and application of endoloops for the treatment of bleeding esophageal varices. Gastrointest Endosc 1999; 50: 677-684
2 Naga MI, Okasha HH, Foda AR et al. Detachable endoloop vs. elastic ligation for bleeding esophageal varices. Gastrointest Endosc 2004; 59: 804-809

${ }^{3}$ McNair AN. Use of mini-loops for the treatment of esophageal varices. Gastrointest Endosc 1998; 48: 556

\section{Corresponding author}

\section{M.-C. Hou, M.D.}

Division of Gastroenterology

Department of Medicine

Veterans General Hospital, No. 201,

Section 2, Shih-Pai Road, Taipei 11217

Taiwan

Fax: $\quad+886-2-2873-318$

E-mail: mchou@vghtpe.gov.tw 